\title{
Projeto Escrever: preparação de alunos do ensino médio para as redações de Enem e de vestibular
}

\section{Angélica Luiza Knapp}

Universidade Federal de Santa Maria | Brasil angelica.knapp@hotmail.com

\section{Rejane Beatriz Fiepke}

Universidade Federal de Santa Maria | Brasil rejanefiepke@hotmail.com

\section{Tamires Regina Zortéa}

Universidade Federal de Santa Maria | Brasil tamiresreginazortea@gmail.com

\section{Resumo}

0 presente relato de experiência refere-se ao projeto de extensão intitulado Projeto Escrever, cujo objetivo é ampliar o ensino de língua portuguesa e redação para Exame Nacional do Ensino Médio (Enem) e vestibulares, destinado a alunos do ensino médio do município de Frederico Westphalen. A partir de autores como Cristóvão Tezza, Carlos Alberto Faraco e Ingedore Koch, foram realizados simulados das provas de redação e em todas as aulas os estudantes receberam temas para a produção de textos. Obteve-se como principais resultados a melhoria significativa na produção de redações por parte dos alunos e a diminuição da insegurança quanto à produção de textos e o tempo destinado a produzir a redação.

\section{Palavras-chave}

Redação; Capacitação; Argumentação. 


\section{Introdução}

O Projeto Escrever teve seu início no ano de 2010, criado pelo professor doutor Elias José Mengarda (in memoriam), docente do Departamento de Ciências da Comunicação da Universidade Federal de Santa Maria (UFSM), Campus Frederico Westphalen. Foi desenvolvido, também, nos anos de 2011, 2012, 2013 e teve seu término em 2014, em virtude do falecimento do orientador. 0 projeto consistia na realização de aulas de redação para alunos do ensino médio em fase preparatória para os vestibulares, sendo firmada a cada edição, uma parceria com alguma escola do município. Na edição de 2014, trabalhada neste relato, o curso foi ofertado para alunos do terceiro ano do ensino médio da Escola Estadual Técnica José Cañellas, de Frederico Westphalen. No ano de 2014 o Projeto foi realizado sob monitoria das autoras, com dez encontros com os alunos participantes. As aulas foram realizadas das $17 \mathrm{~h}$ às $19 \mathrm{~h}$ das segundas-feiras, horário que melhor contemplava os alunos.

O principal objetivo do Projeto Escrever foi preparar os alunos para a realização da prova de redação do Enem, que possui peso relevante na nota final do exame, e redações de vestibulares. Além disso, objetivou-se auxiliar os alunos em sua capacitação para produzirem redações ricas em argumentos, contexto e criatividade e demonstrar a eles a importância da leitura para o desenvolvimento de uma boa escrita e pensamento crítico, um dos itens mais relevantes nas redações atuais.

Trabalhou-se intensamente o gênero textual dissertativo-argumentativo, mais comum e geralmente solicitado em provas de redação. Conteúdos gramaticais também foram elucidados, principalmente no que tange à acentuação, uso de crase, coesão e coerência. Enfatizou-se a importância de os alunos acompanharem os principais acontecimentos da atualidade para possuírem o conhecimento necessário para a formação de sua opinião e exposição da mesma nas redações. Durante o curso foram realizados simulados de redação, que foram corrigidos com a atribuição de apontamentos e sugestão para que os alunos melhorassem sua escrita. Os principais autores utilizados foram Cristóvão Tezza, Carlos Alberto Faraco, Ingedore Koch, Luiz Antônio Marcuschi, Oswaldo Coimbra e Luiz Carlos Travaglia, como pode ser conferido no decorrer do artigo.

Desta forma, o relato é desenvolvido em tópicos, cada um deles explicando uma área abordada pelo projeto. 0 tópico a seguir traz a explanação sobre a importância do Projeto Escrever para os futuros vestibulandos. No terceiro tópico estará presente a Metodologia, e no quarto as considerações finais, que comportam os principais resultados obtidos com esse projeto de extensão realizado por meio da Universidade Federal de Santa Maria. 


\section{A redação}

A redação, considerada parte fundamental em avaliações e vestibulares, é estudada nos níveis fundamental e médio das escolas e institutos, visando o aprendizado da norma culta da língua portuguesa, por parte do aluno, e a preparação do estudante para as provas de ingresso para a Universidade. É importante, no entanto, ressaltar a importância da produção de um bom texto não somente como fator classificatório em provas de avaliação, mas também para o desenvolvimento crítico do aluno, que passa a refletir sobre temas relevantes, começa a expor seus raciocínios de forma ordenada e começa a cogitar sobre soluções para os problemas levantados para a produção da redação.

As redações podem ser produzidas de diferentes formas, desde textos dissertativos, argumentativos até opinativos. Os vestibulares e o Exame Nacional do Ensino Médio (Enem) destacam a importância da redação para ingresso em faculdades e universidades, pois é a partir dela que os avaliadores descobrem o nível de conhecimento do candidato, sua habilidade em desenvolver e explicitar suas ideias, e se ele consegue desenvolver um texto conforme as normas exigidas. 0 tipo de redação mais exigido em provas como essas é o Dissertativo/Argumentativo, e sua estrutura divide-se em Introdução, Desenvolvimento e Conclusão. Mesmo parecendo simples, muitos estudantes possuem grande dificuldade para estruturar corretamente o texto e, portanto, não conseguem desenvolvê-lo.

Como a redação é um dos principais itens avaliados em provas como o Enem e vestibulares, e se tornou imprescindível para o ingresso do aluno nas universidades, é necessário que o aluno seja estimulado, bem como procure aprender as técnicas corretas de produção da redação. Aulas específicas sobre esta área de produção de texto, desta forma, só tendem a somar para o estudante.

\subsection{A redação como forma de avaliação}

0 tipo de redação geralmente utilizado para os vestibulares é o Dissertativo/Argumentativo, que é o mais empregado para que o aluno possa demonstrar o desenvolvimento de seu senso crítico a respeito de determinado assunto. Segundo Boff, Köche e Marinello, conforme Guedes (2009),

[...] todo texto dissertativo precisa argumentar, ou seja, apresentar provas a favor da posição que assumiu e provas para mostrar que a posição contrária está equivocada. Os argumentos baseiam-se nos conceitos apresentados, na 
adequação dos fatos para exemplificar esses conceitos, bem como na correção do raciocínio que estabelece relações entre conceitos e fatos. (BOFF, KÖCHE e MARINELLO, 2002, p. 313).

Cada vez mais, é necessário formar cidadãos que consigam debater sobre os mais variados temas presentes na sociedade. 0 fato de ser dissertativo faz com que o vestibulando possa expor todas as informações que possui sobre o tema da redação, o que mostra o nível de conhecimento do aluno. E o fator "Argumentativo", por sua vez, permite que o estudante possa expor sua opinião crítica sobre o assunto, o que é de grande importância principalmente no caso da prova do Enem.

O Enem exige que o aluno, além de construir uma redação coerente e repleta de informações e conhecimentos, saiba dar uma solução para o problema apresentado na prova. Assim, se torna importante conhecer o gênero dissertativo/argumentativo e estudar os assuntos que obtiveram grande relevância na mídia, no Brasil e no Mundo. Os vestibulares, por sua vez, possuem variações quanto ao gênero exigido nas provas, assim, faz-se necessário estudar as demais tipologias das redações.

\subsection{Os principais critérios de avaliação}

Como forma de exercitar na prática os conteúdos repassados durante as aulas, era solicitado aos alunos a produção de textos dissertativos. Para a correção das redações, posteriormente, eram usados determinados critérios de avaliação que foram propostos por Marcuschi, dentre os quais se destacam: o uso da língua padrão, informatividade, intertextualidade, coesão e coerência. Além de redações produzidas em casa, foram realizados simulados, durante as aulas, para que os alunos aprendessem a lidar não só com os diversificados temas das redações, mas também com o tempo disponibilizado para sua produção.

Os alunos recebiam os seus textos corrigidos segundo os critérios citados e, também, com observações e apontamentos para a melhoria dos mesmos. Assim, a cada redação escrita, conseguiam aprimorar os seus conhecimentos, bem como sua prática de redigir um texto.

\section{Metodologia}

$\mathrm{Na}$ falta de segurança para redigir um texto, que pode resultar na aprovação em um curso de nível superior (preferencialmente público), o aluno que possui condições financeiras suficientes busca nos cursos preparatórios particulares uma melhor preparação, visando seu 
ingresso. Em Frederico Westphalen não existem cursinhos particulares ou pré-vestibulares gratuitos. Essa situação desfavorece o ingresso de jovens que não têm essa oportunidade, principalmente aqueles que são oriundos das camadas mais pobres.

É diante desse contexto e conjuntura vividos pelos jovens de escolas públicas de nossa região que o Projeto Escrever procurou inserir-se e levar sua contribuição, com o objetivo de promover o debate entre professores e alunos que estejam terminando o ensino médio a fim de desenvolver estratégias de produção textual que potencializem a capacidade de argumentação na perspectiva da pragmática da comunicação a partir das várias categorias textuais.

Para a realização dos objetivos propostos, o Projeto Escrever buscou atingir o maior número de estudantes possíveis, sobretudo os que estavam terminando a terceira série do Ensino Médio. Além disso, para melhor ensinar os estudantes e futuros vestibulando foram utilizados autores da área da Linguística, por tratarem, em especial, da gramática, normas da língua portuguesa, coesão, coerência e estrutura correta a ser desenvolvida em uma redação. Os principais autores utilizados como base teórica foram Cristóvão Tezza, Carlos Alberto Faraco, Ingedore Koch, Luiz Antônio Marcuschi, Oswaldo Coimbra e Luiz Carlos Travaglia. A partir do estudo de obras desses autores foram produzidas as aulas que posteriormente foram ministradas para os alunos do ensino médio.

Em Frederico Westphalen, há escolas de Ensino Médio com turmas em todos os turnos, no entanto, ainda se faz necessário considerar os vestibulandos que já se formaram nesse nível de ensino, porém ainda tentam vaga no Ensino Superior. Assim, os horários para desenvolver o Projeto Escrever foram discutidos com os alunos interessados.

Entendemos, também, que este projeto vem ao encontro das necessidades dos vestibulandos que procuram esclarecimentos e aprofundamento de seus conhecimentos a fim de ingressar no ensino superior. Lembrando que, como já citado, em virtude do fato de muitos estudantes não terem as devidas condições de pagar por um curso preparatório, o projeto atinge um aspecto de grande influência nos resultados finais dos vestibulares: a possibilidade de obter conhecimento e preparação além do que é repassado rotineiramente nas salas de aula do ensino médio, e sem ter de arcar com despesas para tal.

Como a Universidade Federal de Santa Maria, Campus Frederico Westphalen, é uma Universidade Pública, entendemos que é uma forma de levar a esses alunos a experiência que a Comissão Permanente de Vestibular (Coperves/UFSM) e outras universidades desenvolveram ao longo dos anos. É uma forma de atender às camadas da população que nem sempre tem oportunidade de ter acesso às informações produzidas dentro da universidade. Temos, na região de abrangência da UFSM/FW, centenas de jovens desejosos de ingressar no ensino superior, mas 
nem sempre podem ou tem condições de se prepararem de forma adequada pela dificuldade de acesso às informações e práticas das universidades.

É nesse sentido que o Projeto Escrever atuava, difundindo junto aos jovens a possibilidade de ingressar na universidade a partir de uma preparação, como a que vinha sendo realizada com os alunos.

Este projeto leva em conta os problemas e dificuldades do vestibulando frente ao desafio de escrever, sobretudo uma redação como as que são exigidas pelos vestibulares ou pelo Enem. Por isso, procurava-se considerar as dificuldades em diversos níveis. 0 primeiro nível levava em conta as dificuldades relacionadas ao domínio gramatical e ao domínio conceitual. Um texto requer um mínimo de estrutura e a, partir disso, considerar a questão do conteúdo. Um texto que apresente bom conteúdo, mas com a estrutura gramatical comprometida acabará por desvalorizar o trabalho como um todo.

O segundo nível que se deve levar em conta é o aspecto emocional do jovem que vai enfrentar o desafio de ingressar na universidade. Além de enfrentar a questão do texto em si, precisa trabalhar os aspectos de equilíbrio, segurança e autodomínio. 0 ato de escrever se tornará desse modo um momento em que o aluno poderá apresentar e revelar tudo o que sabe.

Os trabalhos de Faraco e Tezza (2004) consideram esse desafio propondo amplo estudo e propostas para estudantes ingressantes na Universidade. A primeira ideia é reexaminar o conceito que se tem de língua. Os conceitos desenvolvidos por Faraco e Tezza (2004) apresentam a língua como um conjunto de variedades. Para os autores, a língua não é monolítica, no sentido de que apenas há uma variedade.

Boa parte das dificuldades que nossos jovens enfrentam vem de uma educação com muitas defasagens. A principal, talvez, seja aquela relacionada à própria escola, que durante muito tempo priorizou as normas em detrimento da liberdade de criar e de sentir frente à língua não uma atitude pânico, mas de prazer. Não é o que ocorre na maioria das vezes. As aulas de língua portuguesa se transformam nas mais difíceis da grade curricular. Alguma coisa está errada no enfoque de estudos da língua.

Um bom texto conjuga domínio da estrutura linguística e domínio dos temas que vai desenvolver (FERRARO et al. 2008). Nesse sentido, aqui temos o desafio da leitura. Conforme Koch e Elias (2006) o texto deve ser tomado como concepção de que é o lugar de interação de sujeitos sociais, os quais, dialogicamente, nele se constituem e são constituídos.

Nesse caso, a leitura exige muito mais que o simples conhecimento lingußtico compartilhado pelos interlocutores: o leitor é levado a mobilizar uma série de estratégias tanto de ordem linguß̧tica como de ordem cognitivo-discursiva, com o fim de levantar hipóteses, validar ou não as hipóteses formuladas, preencher as lacunas que o texto apresenta, enfim, participar, de forma ativa, da 
construção do sentido. Nesse processo, autor e leitor devem ser vistos como "estrategistas" na interação pela linguagem (KOCH e ELIAS, 2006, p. 7).

\section{Conclusão}

Ao final, foram percebidos bons resultados. Houve melhora significativa nas redações feitas pelos alunos e eles conseguiram sanar suas principais dúvidas e aplicar os conteúdos aprendidos em aula em suas redações. Por meio das correções realizadas, bem como dos simulados feitos em aula, percebeu-se, também, que a confiança dos estudantes, não só com os temas das redações, mas também com o tempo disponível para a produção da redação, aumentou significativamente.

Observa-se a necessidade do ensino de conteúdos complementares para a realização da redação, pois o vestibular e o Enem originam tensão e insegurança, que devem ser diminuídas com o aumento do aprendizado dos alunos. Essa insegurança surge devido às dúvidas sobre a língua portuguesa e a estrutura para a produção de um bom texto, e com a ampliação, além da sala de aula, do ensino de redação, boa parte do medo que os alunos sentem em fazer o vestibular e/ou Enem não permanece.

0 projeto foi bem sucedido, porque os participantes demonstraram sua melhora nos textos e em suas habilidades. Além da estrutura da redação ter melhorado substancialmente as dúvidas relacionadas a muitas palavras e expressões da língua portuguesa foram sanadas, pois além de aulas sobre estrutura de texto, foram ensinadas regras da gramática.

Ao longo das etapas desenvolvidas, os alunos foram deixando a timidez e o receio de compartilhar suas dúvidas e angústias em relação às provas de vestibulares. Além dos conteúdos programados, houve vários momentos descontra敢os de trocas de experiências e conversas no intuito de fazer com que os alunos se sentissem à vontade para dividirem as suas opiniões e expectativas em relação ao tão temido vestibular.

\section{Referências}

BOFF, Odete Maria Benetti; KÖCHE, VanildaSalton; MARINELLO, AdianeFogali. o gênero textual artigo de opinião: um meio de interação. Disponível em:

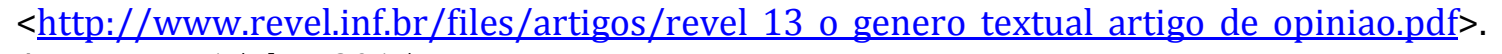
Acesso em: 15 dez. 2015.

COIMBRA, 0. 0 texto da reportagem impressa: um curso sobre sua estrutura. São Paulo: Editora Ática, 2004. 
FARACO, C. A.; TEZZA, C. Prática de texto para estudantes universitários. 12 ed. Petrópolis: Vozes, 2004.

FERRARO, Maria L.; COELHO, Izete L.; GORSKI, Edair M.; RESE, Mara C. F.; CASTELLI, Marco A.; VIEIRA, Milton L. H. (orgs.). Experiência e prática de redação. Florianópolis: Editora da UFSC, 2008.

KOCH, I; ELIAS, V. M. Ler e compreender os sentidos do texto. São Paulo: Contexto, 2006.

MARCUSCHI, L. A. Produção textual, análise de gêneros e compreensão. São Paulo: Editora Parábola, 2008.

Projeto Escrever: high school students preparing for Enem essays and vestibular

\section{ABSTRACT}

This experience report refers to the extension project entitled "Projeto Escrever", whose goal is to expand the Portuguese language teaching and writing for Exame Nacional do Ensino Médio (Enem and vestibular for high school students in the city of Frederico Westphalen (Rio Grande do Sul, Brazil). With the support by authors like Christávão Tezza, Carlos Alberto Faraco and Ingedore Koch, were carried out the simulated writing tests. In the classes the students received themes to writing production. Was obtained as main results the significant improvement in the production of essays by the students and the reduction of uncertainty regarding the production of texts and time for producing the wording.

Keywords

Writing; Training; Argument.

Original submetido em: 30 nov. 2015

Aceito para publicação em: 20dez. 2015
Projeto Escrever: los estudiantes de secundaria que se preparan para las redacciones del Enem y vestibular

\section{RESUMEN}

Este relato de experiencia se refiere al proyecto de extensión titulado "Projeto Escrever", cuyo objetivo es ampliar la enseñanza del portugués y la escritura de redacciones del Exame Nacional do Ensino Médio (Enem) y vestibular, dirigido a estudiantes de secundaria en la ciudad de Frederico Westphalen (Rio Grande do Sul, Brasil). A partir de autores como Christóvão Tezza, Carlos Alberto Faraco y Ingedore Koch, se realizaron simulaciones de las pruebas de escritura. En las clases los estudiantes recibieron temas para la producción de textos. Se obtuvo como resultados principales la mejora significativa en la producción textual de los alumnos y la reducción de la incertidumbre con respecto a la producción de textos y el tiempo destinado a su producción.

\section{Palabras clave}

Escritura; Capacitación; Argumentación.

Sobre os autores:

Angélica Luiza Knapp

Acadêmica de Comunicação Social - Habilitação: Jornalismo, da Universidade Federal de Santa Maria, Campus Frederico Westphalen. 


\section{Rejane Beatriz Fiepke}

Acadêmica de Comunicação Social - Habilitação: Jornalismo, da Universidade Federal de Santa Maria, Campus Frederico Westphalen.

\section{Tamires Regina Zortéa}

Acadêmica de Comunicação Social - Habilitação: Jornalismo, da Universidade Federal de Santa Maria, Campus Frederico Westphalen. 